\title{
Indonesia's policy on e-commerce regulation and its challenges
}

\author{
Peronika Simanjuntak ${ }^{\mathrm{a}, 1, *}$ \\ ${ }^{a}$ Faculty of Social and Political Science, Airlangga University, Surabaya, Indonesia \\ ${ }^{1}$ veronika91@ymail.com * \\ * corresponding author
}

\begin{abstract}
ARTICLE INFO ABSTRACT
Article history

Received September 4, 2019

Revised September 30, 2019

Accepted October 14, 2019

Keywords

E-Commerce Regulations

Globalization

Indonesian's E-Commerce

Policy

Southeast Asia

Technology and Information

Globalization has a significant influence on many aspects, such as social and economic, and its effect cannot be separated from technological developments that change human behavior in conducting economic activities. Those change including the emergence of trade that uses online-based transactions or ecommerce. E-commerce considered to have a significant influence on the country's economic growth and predicted to flourish over the years. Aware of its enormous potential and growth in Southeast Asia, countries in this region began to regulate e-commerce, and one of them is Indonesia. The authors find that in the past few years, Indonesia has been more active in making and changing its policies to regulate online-based trading, while at the same time trying to protect its domestic small-medium enterprises (SMEs). Nowadays, Indonesia's ecommerce market is relatively minor compared to its neighbors. However, believed that the growth of the middle class, the improvement of internet users, and the intensive improvements in Indonesia's logistics and infrastructure that conducted in recent years, will have a significant effect on the Indonesian ecommerce market. In this paper, the authors will explain the policy of Indonesia in regulating e-commerce and its challenges. The discussion in this paper will be divided into three sections. The first part is the conceptual foundation. The second part is about the development of e-commerce in Indonesia. The third part is the Indonesian government's policy in managing e-commerce and its challenges.
\end{abstract}

\section{Introduction}

As one of the highest growth rates region in the world, Southeast Asia has not apart from the influence of technological developments on its social and economic aspects. The rapid technological developments of the last two decades and the emergence of Internet technology had a significant effect on the way people perform economic activities, including emergence concept of electronic commerce (e-commerce). E-commerce is a new concept, but with its rapid development, this industry sector becomes increasingly important [1]. Also, the efficiency of this form of trading leads to the development of other industrial sectors.

Based on the explanations, it is normal that countries in Southeast Asia begin to pay more attention to this type of trading model. Besides being aware of the enormous potential of online trading for economic growth, they are also aware of the threat posed, especially for small and medium enterprises (SMEs). In Indonesia's case, the rules on electronic commerce are not new. However, this issue is starting to get more attention especially since the elimination of the ecommerce industry from the list of detrimental investments. Which means that the government began to receive foreign investment in the domestic e-commerce industry sector? Furthermore, the government began to issue other policies related to the regulation of the domestic e-commerce industry. 
This study describes the relationship between globalization, technological developments and electronic commerce and how these issues affect Indonesia's policy. Globalization and rapid technological developments in the last few years have given rise to a new concept in commerce, which is trade that utilizes internet technology. Recently, this issue attracts the attention of many countries. The immense potential of this trade raises Indonesia's awareness to regulate its growth, taking advantage of economic growth, and protecting SMEs in the country.

\section{Globalization, The Development of Technology and E-commerce}

Globalization is a form of interconnection between countries in terms of economy through the form of free trade. The word integration, which means integer or the act of combining one into a whole in defining globalization [2]. There is a paradigm shift from nation-state and national economy to a global economy, due to free trade, mobility capital, and migration that are difficult to control. As Daly explains, integration in the concept of globalization itself will blur the boundaries between countries, as well as its actors, so that other issues develop into cross-border [2]. The development of information technology is a factor that has a significant influence on such integration.

Globalization and the development of technology and information have complementary relationships due to their mutual benefits [3]. The rapid development of technology and information in the last two decades has made the world became shrinking, and distances become a concept that is no longer relevant in human interconnection. In the era of globalization, the development of technology and information has a considerable influence on the way people in conducting economic activities. As a result, countries, corporations, and individuals are in a situation where they must restructure and position themselves to efficiently utilize global resources and maximize profits derived from global markets [4]. The development of the internet because of rapid technological developments in the 21st century may cause the development of e-commerce.

As a new concept, e-commerce has a significant influence on changing the shape of economic activity and affecting major industrial sectors such as communications, finance, commerce, health, even governance [5]. The definition of e-commerce is the purchase and sale of goods and services that use the Internet media. In other literature, the concept of e-commerce refers to commercial or non-profit business activities with the application of modern computer technology, network technology, and modern information communication technology [6]. Sometimes, this process is also referred to as e-business. However, the term e-business is often used to define a broader process, such as the way companies do business through the internet.

E-commerce is formed due to the development of modern information technology and global economic integration. In other words, e-commerce is a new form of commerce that comes with the application of electronic information technology in the field of trade [6]. The rapid development of e-commerce may cause chaos in the retail industry [7]. The reason is, they are demanded to immediately adjust to changes with consumer behavior in the digital era as nowadays. Also, the speed of technological development and the transition to the digital era will have a significant impact on global trade [7].

Moreover, the rapid development of e-commerce, leading to the thought of frictionless economic or known as the concept whereby economic activity occurs with almost zero transaction costs since the loss of existing intermediaries will drastically reduce transaction costs [8]. Reduced transaction costs will encourage the entry of new businesses that affect increasing competition. So, the result is increasing pressure on the producer to provide a lower cost to the consumer. Besides, online transactions also lead to a shift in market power from producer to consumer because internet media allows consumers to find lower prices among available traders [9]. Overall, e-commerce can significantly improve economic efficiency, improve competitiveness, improve resource allocation, and promote long-term growth [8].

The growth of e-commerce has an impact on the number of consumer interest in online transactions and leads to an increase in their consumption. With the growing e-commerce, it will have a significant role in improving the growth of a country in the 21st century [10]. There are five reasons why e-commerce can be a crucial factor for economic growth, (1) e-Commerce is closely related to the development of information and technology, (2) it is based on internet and information 
(3) e-commerce is a form of innovation from traditional economic and business activities, (4) have an ecosystem chain, and (5) e-commerce has strong permeability [11].

There is a close relationship between e-commerce and the national economy [6]. The microscopic behavior of e-commerce has a positive effect that will inevitably lead to macroeconomic development and encourage national economic growth. In Liu's research, ecommerce in China encourages the development of high-tech companies, encourages structural optimization and improves traditional industries, as well as being a growth point of the modern logistics industry and China's economic development. The result is that at present, China is a country with the world's largest e-commerce industry and transactions because of it's rapid growth of the e-commerce industry, especially since 2006. These developments cannot be separated from the pleasant environment, including infrastructure, government policies, and markets favorable to industrial development. Even the monetary crisis of 2008 did not affect the development of ecommerce in China. China's total volume of e-commerce transactions in 2008 increased by more than 40 percent. During the crisis, the e-commerce industry in China has a vital role in helping small and medium-sized businesses overcome difficulties by boost domestic demand and create jobs [6]. Furthermore, the development of e-commerce provides a chilling effect for the Chinese economy, such as encouraging the development of the computer industry, the Internet technology industry and the logistics industry, and providing more labor and related practitioners [11]. The explanation proves that e-commerce progress also brings other industry advances.

The magnitude of the impact of e-commerce, become new attention for many countries in terms of regulating and taking advantage of the interests of the domestic economy. Southeast Asia as a region with a prominent level of technology adoption, did not escape the issue of the development of digital commerce, and Indonesia is one of them. Departing from the issue, the author will try to discuss it in the next explanation.

\section{The Development of E-commerce in Indonesia}

By now, the Asia and Pacific region is the largest e-commerce market in the world, with China accounting for $47 \%$ of total sales in the region [12]. In this case, the Southeast Asian region is very lagging behind with other regions. Inequality of technology adoption is an underlying factor that is very influential on the backwardness of Southeast Asia. It is that only $29 \%$ of Southeast Asian populations have access to the internet network by 2013 [13], and $44 \%$ by 2015 in other literature [14]. In another study, it mentioned only six countries, which are Singapore, Indonesia, Malaysia, Philippines, Vietnam, and Thailand, while not mentioning the other four, Cambodia, Laos, Myanmar, and Brunei Darussalam, when explaining e-commerce in Southeast Asia. The reason is, those four countries have almost no e-commerce to discuss [15].

Of the six countries mentioned by Olsen et al., Malaysia and Thailand are the largest e-commerce markets in Southeast Asia by 2015 [16]. The e-commerce market in those six countries estimated to be worth about US $\$ 7$ billion by 2015 [13], but that number represents less than $2.5 \%$ of overall retail sales in Southeast Asia [11]. The number is indeed insignificant compared to the size of Southeast Asian populations [13]. Nevertheless, most of the Southeast Asian populations that connected to the Internet do economic activities online as often as populations in developed countries [15]. The explanation shows that Southeast Asia is a region with an exciting potential as a next e-commerce boom, especially if we look at the rapid development of technological adoption in Vietnam and Indonesia within a few years [11]. Besides, trade using social commerce is high in Southeast Asia, with a percentage of 30\% of all online sales in the region by 2016 and showing an ever-increasing trend [12].

Social media platforms are a dynamic, efficient, and essential tool for SMEs that generally have limited resources [12]. At present, Thailand is the largest social trading market in the world, with $51 \%$ of online shoppers shopping using social media platforms. Malaysia and Indonesia have not much different comparison with Thailand, with an average of 33\% of online shoppers shopping using social media platforms [12]. Also, Southeast Asia has a relatively young population, and proper infrastructure development is one of the main drivers of the growth of the e-commerce industry in the region. The growth of active social media users in Southeast Asia is over 20\%, with Vietnam and Indonesia as the highest growth-number countries, with $41 \%$ and $39 \%$ respectively [17]. 
Social media platform proves to be a positive platform for e-commerce growth in Southeast Asia, and one of the critical drivers of this development is its high middle-class growth, changes in consumption and purchase patterns, and the growing number of mobile payment systems in the region. However, although it is considered to have enormous growth potential, the e-commerce market in Southeast Asia has many obstacles. Frost and Sullivan's study also points out that ecommerce is a crucial driver of regional growth in Southeast Asia, but its complexity is one of the biggest challenges faced by Southeast Asian countries in developing this industry. For example, apart from Malaysia and Singapore, credit card ownership rates in Southeast Asia are meager, less than 7 percent of the total population. Also, in some countries, more than half the population has no bank account. Logistics is another issue that hinders e-commerce growth, especially in areas with complex geography such as Indonesia and the Philippines [16]

The challenges for e-commerce in Southeast Asia, which is (1) Infrastructure and poor connectivity. Internet connectivity in Southeast Asia is relatively low, and the only country with strong Internet connectivity is Singapore, (2) Lack of adequate human resources, many companies are struggling to grow their businesses online because they lack the skilled workers about online technology and transactions, especially in SMEs [13]. Moreover, these obstacles make the challenge even harder because they lead to other challenges directly related to previous challenges: (1) Skepticism About Competing Capabilities, Southeast Asian SMEs lag behind other regions [13]. In a survey conducted by CIMB, explained that Southeast Asian entrepreneurs still have the perception that e-commerce businesses cost more than their profits. Besides, SMEs in Southeast Asia believe that most of the hype surrounding e-commerce is overstated [15], (2) Fear of online payment systems; many traders and consumers in Southeast Asia are less interested in online transactions. They still prefer the traditional transaction model by way of cash. Therefore, the governments of Southeast Asian countries have begun developing regulations for data protection, preventing cybercrime, and encouraging online purchases [13].

In Indonesia's case, this country has the status of being one of the largest economies in Southeast Asia, possibly Asia Pacific, and one of the fastest internet adoption nations in the world. So, it is normal that e-commerce in Indonesia began to grow [18]. However, the issues mentioned earlier, basically not much different from Indonesia. Indonesia is listed at the bottom $30 \%$ position in the ranking of countries to do business, which means that Indonesia is one country that has a bad investment environment, from a list of 189 countries in the World Bank report. The cause is not much different from most of the Southeast Asian countries, such as inadequate infrastructure, lack of regulation and protection from the government, and inadequate resources. Even though Indonesia is still considered as a potential country after India and China, because of its large population, the economic potential of e-commerce is still not widely utilized. In its development, the Indonesia government began to realize the potential of e-commerce business in the country and began more active in drafting regulations on this business. [19] Stating that there is urgency regarding the need for the preparation of e-commerce regulation in Indonesia (Ministry of Trade of Republic of Indonesia 2015), followed by the emergence of the new e-commerce roadmap of Indonesia.

\section{Indonesian Policy in E-Commerce Regulation and Its Challenges}

The development of e-commerce business or online sales in Indonesia has increased dramatically since the last few years, especially since various smartphone vendors entered the Indonesian market. According to Agus Tjandra, Vice Chairman \& Foreign Relations of the E-Commerce Association of Indonesia (idEA), the growth of e-commerce business in Indonesia is remarkable, and the growth is accompanied by increased e-money compared to five years ago. Meanwhile, according to research from Social Research \& Monitoring soclab.com, quoted by news portal Indonesia, Tribun News, internet users in Indonesia reached 93.4 million, with 77 percent of them looking for product information and online shopping in 2015. In 2016, the number of online shoppers reached 8.7 million people, with a transaction value of about \$ 4.89 billion US dollars [20].

The e-commerce industry in Indonesia is growing while the issue of e-commerce regulation in Indonesia has only started in 2016 [21]. In that year, the government began to have a commitment to provide ease of investment that is useful for the progress of the digital ecosystem industry in Indonesia and as well as protection for SMEs who will enter the digital world. As with opening up e-commerce investment for foreign, that is by removing e-commerce business from a negative list of 
investments in Indonesia in 2016 [22]. This step is considered as the first step in Indonesia in its effort to regulate the e-commerce industry. With the abolition of e-commerce from a negative list, it means that the Indonesian government is beginning to provide significant opportunities for foreign investment, including e-commerce companies, to invest in Indonesia, although there are prerequisites to allow only 100 percent of foreign ownership with a minimum investment of 100 billion \$ US 7.3 billion in exchange rates in 2016) or businesses that generate 1,000 jobs, and limit foreign ownership to 49 percent for business investments below 100 billion [18].

Although relatively slow, the government's efforts seen as a positive step if the Indonesia government wants to encourage significant e-commerce investments from large businesses while protecting e-commerce players from local small and medium enterprises (SMEs) in Indonesia. In addition to efforts to open investment in e-commerce business, the government has also issued a new e-commerce roadmap as a step to welcome the free trade of Asean Economic Community (TAF), whose draft has been signed by President Joko Widodo in 2017. In the roadmap, the Indonesia government is targeting that e-commerce business in Indonesia can reach US \$ 130 billion by 2020 [14].

There are seven main points in the e-commerce roadmap in Indonesia, named (1) utilization of blueprint National Logistics System (SISLOGNAS) to increase the delivery speed to reduce shipping costs; (2) finalize RPP e-Commerce that can channel government grants / subsidies to digital SMEs and startup e-Commerce, (3) build consumer trust through regulation, protection of industry players, simplify business licensing registration for e-commerce players, developing the National Payment Gateway in stages that can improve electronic retail payment services (4) improving the national communications infrastructure as the backbone of e-Commerce industry growth; (5) simplifying taxation procedures for e-commerce starters, providing tax incentives for ecommerce investors, and tax incentives for e-commerce startup, (6) provide education for the entire e-commerce ecosystem, and (7) increased awareness of online and public traders against cybercrime and about the importance of electronic transaction security [14].

Besides, the Indonesian government is also committed to improving Indonesia's internet and communications infrastructure with the Palapa Ring 2 program, which targeted for completion by 2018. To date, the Indonesian government's seriousness is seen by improving the logistics issue, by improving infrastructure on a large scale in all provinces in Indonesia, as well as the start of digitalization as required by all toll roads in Indonesia to use non-cash payment systems, and the National Payment Gateway (NPG) policy to be implemented by Bank Indonesia on June 30, 2018 [23]. By looking at Indonesia's efforts through the issuance of new policies in regulating the ecommerce industry, there are undoubtedly many challenges that Indonesia will face in the future.

Regarding internal challenges, there is a tendency that developing countries are less consistent in implementing regulations. Often there are different regulations between government agencies, as well as the possibility of oligarchic politics, as established industries are potentially threatened with the effectiveness of the e-commerce industry. Another issue is taxes, with increasing electronic transactions, the Indonesian government should unquestionably think about the reduced state revenues from the tax sector on the offline retail industry, which is likely to be rivaled by the online retail industry. The transition of taxes would take some time, given to the present; the socialization of the tax has not been published. There are also other issues, such as inadequate infrastructure. As for the external challenges that Indonesia must face is the lack of integration between countries in Southeast Asia. Since the e-commerce industry is part of cross-border trade, the differences in interest, development, and sense of urgency often become an obstacle for countries to cooperate. Given China's aggressiveness to the e-commerce market in the region, the urgency to work together is becoming increasingly important.

\section{Conclusion}

Given its rapid development and the enormous impact of e-commerce on a country's economy, governments need to build a positive environment for e-commerce industries to take advantage of these new market opportunities. It will require an active role from the public sector because as a newly emerging industry, likely that the market failure rate in Indonesia will be high. The challenges faced by Indonesia will be overwhelming, especially in the transition phase towards the digital economy in Indonesia. 
Most Southeast Asia countries may also face Indonesia's challenges. The similarity of these potentials and challenges should increase the awareness of countries in the Southeast Asia region to be more synergistic in developing the e-commerce industry.

\section{References}

[1] G. A. Jentz, R. L. Miller, and B. Franc, “Cross, West’s Business Law.” Alternate Edition, 2002.

[2] S. Subba Rao, G. Metts, and C. A. Mora Monge, "Electronic commerce development in small and medium sized enterprises: A stage model and its implications," Bus. Process Manag. J., vol. 9, no. 1, pp. 11-32, 2003.

[3] K. Chareonwongsak, "Globalization and technology: how will they change society?," Technol. Soc., vol. 24, no. 3, pp. 191-206, 2002.

[4] O. M. Obafemi, "The challenges of globalization on e-commerce in Nigeria," Ahmadu Bello University, 2012.

[5] M. L. Markus and C. Soh, "Structural influences on global e-commerce activity," in Advanced Topics in Global Information Management, Volume 2, IGI Global, 2003, pp. 1-13.

[6] S. Liu, "An Empirical Study on E-commerce's effects on Economic Growth," in 2013 Conference on Education Technology and Management Science (ICETMS 2013), 2013.

[7] M. Kenney and J. Curry, "E-commerce: Implications for firm strategy and industry configuration," Ind. Innov., vol. 6, no. 2, pp. 131-151, 1999.

[8] Z. Hoq, M. S. Kamal, and A. H. M. E. H. Chowdhury, "The economic impact of e-commerce," BRAC Univ. J., vol. 2, no. 2, pp. 49-56, 2005.

[9] R. J. Gordon, "Does the" new economy" measure up to the great inventions of the past?," J. Econ. Perspect., vol. 14, no. 4, pp. 49-74, 2000.

[10]S. Vanichviroon, "E-Commerce Contribution to Economic Growth: The Case of Thailand," in Information Technology and Economic Development, IGI Global, 2008, pp. 140-154.

[11]S. Feindt, J. Jeffcoate, and C. Chappell, "Identifying success factors for rapid growth in SME ecommerce," Small Bus. Econ., vol. 19, no. 1, pp. 51-62, 2002.

[12]F. Hoppe, S. Lamy, and A. Cannarsi, "Can Southeast Asia live up to its e-commerce potential," Bain Co., vol. 16, 2016.

[13] R. Kirchenbauer, "E-Commerce in Southeast Asia: Major Challenges," www.investasian.com, 2016.

[14] S. Tangkary, "Siap menjadi raja digital ASEAN?," Makassar, 2016.

[15]C. Lee and S. B. Das, "E-Commerce \& ASEAN Economic Integration," 2018.

[16]D. T. Cris, "E-Commerce Set to Grow Rapidly in South-East Asia," internetretailing.com.au, 2016.

[17] S. Kemp, "Digital in 2017: Global overview," We are Soc., vol. 24, 2017.

[18]H. Rosdiana and R. Kusumastuti, "The Protection of Information Privacy in Indonesia's E-commerce: A Legal Approach Perspective," KnE Soc. Sci., pp. 59-68, 2017.

[19]E. Makarim, "Kerangka Kebijakan dan Reformasi Hukum Untuk Kelancaran Perdagangan secara Elektronik (E-Commerce) di Indonesia,” J. Huk. Pembang., vol. 44, no. 3, pp. 314-337, 2014.

[20]H. Feryanto, "Transaksi e-Commerce di Indonesia Pada 2016 Mencapai 4,89 Miliar Dolar AS," www.tribunnews.com, Feb-2017. .

[21] M. T. Kinda, E-commerce as a Potential New Engine for Growth in Asia. International Monetary Fund, 2019.

[22] The Jakarta Post, "Indonesia to finalize regulation on e-commerce," www.thejakartapost.com, Jakarta, May-2016.

[23] K. David, "The Dual Challenge of E-Commerce Regulations in Indonesia," www.export.gov, 2017. 